\title{
Implementation of Competency-Based Curriculum in Medical Education: Perspective of Different Roles
}

\author{
Aline Guerra Aquilante, ${ }^{1}$ Roseli Ferreira da Silva, ${ }^{1}$ Mariza Borges Brito de Souza, ${ }^{2}$ \\ and Renata Gianecchini Bongiovanni Kishi ${ }^{1}$
${ }^{1}$ Departamento de Medicina, Universidade Federal de São Carlos (UFSCar), Rodovia Washington Luís, km 235, Monjolinho, 13565-905 São Carlos, SP, Brazil
${ }^{2}$ Departamento de Enfermagem, Universidade Federal de São Carlos (UFSCar), Rodovia Washington Luís, km 235, Monjolinho, 13565-905 São Carlos, SP, Brazil \\ Correspondence should be addressed to Aline Guerra Aquilante, aline@ufscar.br
}

Received 7 May 2012; Accepted 21 June 2012

Academic Editors: A. E. Kelly, B. Marlow, and R. Martens

Copyright () 2012 Aline Guerra Aquilante et al. This is an open access article distributed under the Creative Commons Attribution License, which permits unrestricted use, distribution, and reproduction in any medium, provided the original work is properly cited.

\begin{abstract}
This cross-sectional case study investigates the curriculum implementation at the School of Medicine at the Universidade Federal de São Carlos (UFSCar), comparing the perspectives of the different participant types involved in this training (i.e., students, lecturers, and preceptors) and the programme goals. The sample included 22 lecturers, 55 students, and 16 preceptors. The researchers created a structured questionnaire based on study indicators extracted from the following aspects of the educational programme: teaching and learning process, integration of competency areas, teaching and learning scenarios, integration of theory and practice, and assessment. A Likert scale with four response options was used to score the respondents' choices. The participants answered the questionnaire online, and the responses were entered into a MySQL database. Using this database, an analysis was conducted based on the subjects' responses and the indicators. Comparative analysis was performed using the bootstrap method for responses and analysis feasibility with a 5\% empirical significance level. The teaching and learning process, integration of theory and practice, and assessment indicators were in agreement with the educational programme, while integration of competency areas and teaching and learning scenarios require greater attention to establish consistency with the educational programme and training qualifications.
\end{abstract}

\section{Introduction}

The medical education programme at Universidade Federal de São Carlos (UFSCar) in Brazil has an innovative competency-based curriculum. The programme uses an integrated curriculum and active methods, such as problembased learning (PBL) and practice-based learning [1].

UFSCar graduates are trained in 3 areas of medical practice competency: health (individual and collective), management (work organisation and care management), and education.

This six-year course has three educational units: professional practice (PP), professional practice simulation (PPS), and elective.
In PP, the professional practice begins at real-world scenarios in the first year and continues throughout the programme, expanding knowledge and increasing autonomy in performing the tasks studied.

The PPS consists of two curricular activities: professional practices simulation activities (PPSAs), in which students primarily work with simulated patients (using actors provided by the school), and problem situations activities (PSAs), in which cases written by lecturers are used to simulate professional practice.

In the elective unit, the student prepares a teaching plan with the support of a mentor lecturer based on his educational needs and competency profile, which may be developed either inside or outside the University. 
Rooted in concepts of social constructivist learning, the curriculum is competency-based and uses real-life professional practice scenarios, thereby providing a strong integration of theory and practice. Assessment is criterionreferenced and includes cumulative and formative perspectives [1].

\section{Methods}

This cross-sectional case study examines the UFSCar medical education programme innovative curriculum, which is competency-based and integrated, and uses active teaching and learning methods.

The objective of the study was to evaluate the implementation of UFSCar's medical education curriculum and compare the participants' perspectives by group (i.e., students, lectures, and preceptors) with the goals of the educational programme.

2.1. Population and Study Sample. The study population was composed of the following three groups and corresponding inclusion criteria: lecturers must have at least two years of relevant experience in the medical programme; preceptors must have at least two years of relevant experience; students must be in their first to fourth years of study. A pilot sample with a similar population was used to validate the questionnaire and determine the sample size, which encompassed 22 lecturers, 16 preceptors, and 55 students. Questionnaires were then sent to the participants.

At the time of this study, the different professional practice locations attended by the students were as follows: the Family Health Unit (FHU, 100\%), the Integrated Health Centre (IHC, 25\%), the Specialty Centre (34\%), the School Health Unit (SHU, 47\%), and the Teaching Hospital (30\%). In addition, other locations were also represented (41\%), including the Basic Health Units (BHU), emergency care, and other hospitals.

Following approval from UFSCar's Research Ethics Committee, data collection was performed from December 2009 (when the pretest was initiated) to December 2010 (when the required sample size for all three groups was reached).

2.2. Study Variables. The indicators (see appendix) were based on curriculum assumptions and guidelines as detailed in UFSCar School of Medicine's educational programme. Although the questionnaire was constructed using quantitative strategies, qualitative indicators were used to assess the responses.

2.3. Data Collection Instrument. The researchers constructed a structured questionnaire using the study variables: teaching and learning process, integration of competency areas, teaching and learning scenarios, integration of theory and practice and assessment. The lecturer, students, and preceptor questionnaires contained 24, 36 and 25 questions, respectively. The differences in the number of questions reflect each role's differing level of involvement in the curriculum. The number of questions used for lecturers, students, and preceptors, respectively, for each variable was as follows: teaching and learning process $(7,10,6)$; integration of competency areas $(5$, $9,4)$; teaching and learning scenarios $(1,6,5)$; integration of theory and practice $(7,7,6)$; and assessment $(4,5,4)$.

The use of a four-point Likert scale allowed numerical analyses of the respondents' score choices to be conducted. The scale was as follows: always ( 4 points), often ( 3 points), rarely ( 2 points), and never ( 1 point).

2.4. Data Collection. Once the participants were identified, they received emails explaining the survey and its purpose and containing the website address and password for the restricted area. The password was randomly generated and encrypted in the database.

Once on this website, the respondent was prompted to either agree or decline to participate in the research. If the participant agreed, he could access and complete the questionnaire; otherwise, he was disconnected from the system. Each participant received the terms of free and informed consent and a group-specific questionnaire.

An initial website was created by the assessment team at the Centro de Estudos do Risco (CER) in UFSCar's Department of Statistics (DEs-CCET). The purpose of this website was to record data, present the project, and create a restricted area to present select individuals' responses and future analyses. MySQL, a database management system that uses SQL (Structured Query Language) as an interface to build a database with simple importing and exporting, was used to develop the system resources. In addition, SQL was related to $\mathrm{R}$ language (cran.rproject.org) to perform dynamic analysis.

2.5. Data Analysis. After completing the questionnaire, the participants' answers were incorporated into the MySQL database. Only the database administrator, the assessment team, had access to the database, thereby ensuring data confidentiality.

Using this database, the participants' responses and indicators were analysed. Using the bootstrap method [8] for responses and analysis viability, comparative analysis was conducted with a 5\% significance level. A boxplot was created to compare the empirical distribution of each group's responses.

\section{Results}

The questionnaire was completed by 23 lecturers, 80 students, and 17 preceptors with connections to the UFSCar School of Medicine, resulting in a total sample of 120 subjects. Of the 23 lecturers who responded to the questionnaire, $52 \%$ were male and $48 \%$ female, with a mean age of 43.9 years. The median year in which they joined the course was 2006. The distribution of activity time according to curricular activity was as follows: $43 \%$ in PPSA, 35\% in PSA, and $22 \%$ in PP. Of the 80 students who responded to the questionnaire, $48 \%$ were male and $52 \%$ female, with a mean age of 22.5 years. The median year in which they joined the course was 2008. Of the 17 preceptors, 35\% were male and 
TABLE 1: Bootstrap 95\% confidence intervals for the teaching and learning process indicator.

\begin{tabular}{lc}
\hline Subjects & MD [LL; UL] \\
\hline Lecturers & $3.29[3.21 ; 3.37]$ \\
Students & $3.21[3.17 ; 3.25]$ \\
Preceptors & $3.53[3.43 ; 3.63]$ \\
\hline
\end{tabular}

MD: median LL: lower limit of the confidence interval, UL: upper limit of the confidence interval.

TABLE 2: Bootstrap 95\% confidence intervals for the integration of competency areas indicator.

\begin{tabular}{lc}
\hline Subjects & MD [LL; UL] \\
\hline Lecturers & $2.63[2.5 ; 2.77]$ \\
Students & $2.63[2.58 ; 2.69]$ \\
Preceptors & $3.19[3.03 ; 3.35]$ \\
\hline
\end{tabular}

MD: median, LL: lower limit of the confidence interval, UL: upper limit of the confidence interval.

TABLE 3: Bootstrap 95\% confidence intervals for the teaching and learning scenarios indicator.

\begin{tabular}{lc}
\hline Subjects & MD [LL; UL] \\
\hline Lecturers & $2.61[2.26 ; 2.96]$ \\
Students & $2.50[2.42 ; 2.58]$ \\
Preceptors & $3.05[2.88 ; 3.22]$ \\
\hline
\end{tabular}

MD: median, LL: lower limit of the confidence interval, UL: upper limit of the confidence interval.

$65 \%$ female, with a mean age of 43.3 years. The median time spent acting as preceptor in the medical programme was 3 years, with $35 \%$ of preceptors working in $\mathrm{FHU}$ and $65 \%$ in BHU.

To compare the different groups' perspectives and the study indicators, a comparative analysis was performed with a $5 \%$ empirical significance level using the bootstrap method [8]. A boxplot was used to compare the empirical distribution of responses for each group. The tables and Figures below present confidence intervals between research subjects and comparisons between the responses for each group of respondents to assess whether the groups responded similarly to the questionnaires. We observed that the response variability decreases as the number of respondents increases.

3.1. Constructivist Approach to the Teaching and Learning Process. The teaching and learning process confidence intervals show an intersection between lecturers and students, indicating that their opinions are equivalent at a $5 \%$ significance level (Table 1, Figure 1. However, the preceptors' responses were statistically different from those of the other two groups at this significance level.

3.2. Connection between Competency Areas. In this study, the integration of competency areas indicator showed an intersection between the lecturer and student groups but not with the preceptor group, indicating that the opinions
TABLE 4: Bootstrap 95\% confidence intervals for the integration of theory and practice indicator.

\begin{tabular}{lc}
\hline Subjects & MD [LL; UL] \\
\hline Lecturers & $2.89[2.8 ; 2.99]$ \\
Students & $3.00[2.97 ; 3.03]$ \\
Preceptors & $3.52[3.39 ; 3.64]$ \\
\hline
\end{tabular}

MD: median, LL: lower limit of the confidence interval, UL: upper limit of the confidence interval.

TABLE 5: Bootstrap 95\% confidence intervals for the assessment indicator.

\begin{tabular}{lc}
\hline Subjects & MD [LL; UL] \\
\hline Lecturers & $3.27[3.15 ; 3.39]$ \\
Students & $2.93[2.85 ; 3.01]$ \\
Preceptors & $3.35[3.12 ; 3.57]$ \\
\hline
\end{tabular}

MD: median, LL: lower limit of the confidence interval, UL: upper limit of the confidence interval.

of students and lecturers are statistically equal at a 5\% significance level, while the opinions of preceptors differ (Table 2, Figure 2).

3.3. Development of Pedagogical Actions Involving Different Learning Scenarios. In assessing learning scenarios, we observed an intersection in the confidence intervals of lecturers and students and a small intersection in the confidence intervals of lecturers and preceptors. The lectures' responses are highly variable because only one question was considered an indicator in this area. It is also important to note that lecturers do not participate directly in practice scenarios. We can therefore conclude that the lecturer and student groups share the same opinion, while the response of the preceptor group differs from that of the other two groups (Table 3, Figure 3).

3.4. Integrating Theory and Practice. In this study, the responses for the integrating theory and practice indicator have no statistically significant differences for lecturers and students, while the preceptors' responses differ significantly from the other two groups (Table 4, Figure 4).

3.5. Criterion-Referenced Assessment. Regarding the assessment indicator, we noted that the opinions of preceptors and lecturers were statistically similar, while the students' opinions diverged from the other two (Table 5, Figure 5).

\section{Discussion}

The constructivist perspective is rooted in Vygotsky's theories, which emphasise the relationship between a student's current skills and knowledge, the zone of real development, and what he should learn next to achieve a particular goal, the zone of proximal development $[5,7,9]$. We found that lecturers and students believe that curricular activities usually encourage the development of critical reflective capacities and always encourage the development of the 


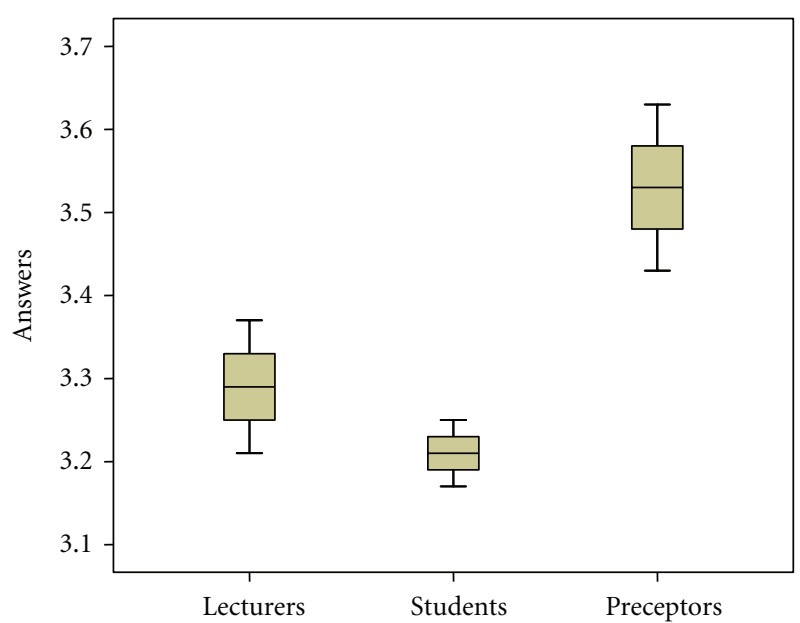

FIGURE 1: Boxplot for the teaching and learning process indicator.

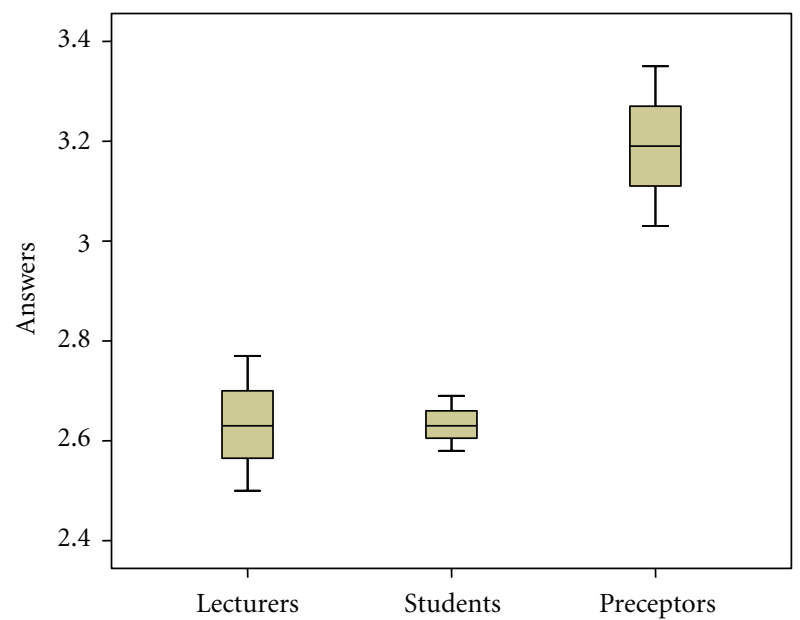

FIGURE 2: Boxplot for the integration of competency areas indicator.

capacity to learn how to learn. The preceptors reported that curricular activities always encourage the development of critical reflective capacities. These results are consistent with the constructivist approach to the teaching and learning process, which comprises a dialogic process aimed at building consensus, developing critical reflective capacities, and emphasising discovery learning to understand a problem. To achieve these goals, problems or issues that guide the discovery process must be personal and socially relevant $[2,4,10]$. Using strategies taught by the lecturer, students construct their own meaning based on the interactions between prior knowledge and current learning experiences. When a problem is presented in a group tutorial, students are encouraged to construct new knowledge by identifying what they already know about a particular problem, generating questions for further study and then sharing what they learned with their peers $[5,10]$. The fundamental role of the lecturer is that of a guide and facilitator of knowledge construction [2]. In this study, lecturers and students agreed that the teaching and learning process usually favours the construction of a participatory relationship between

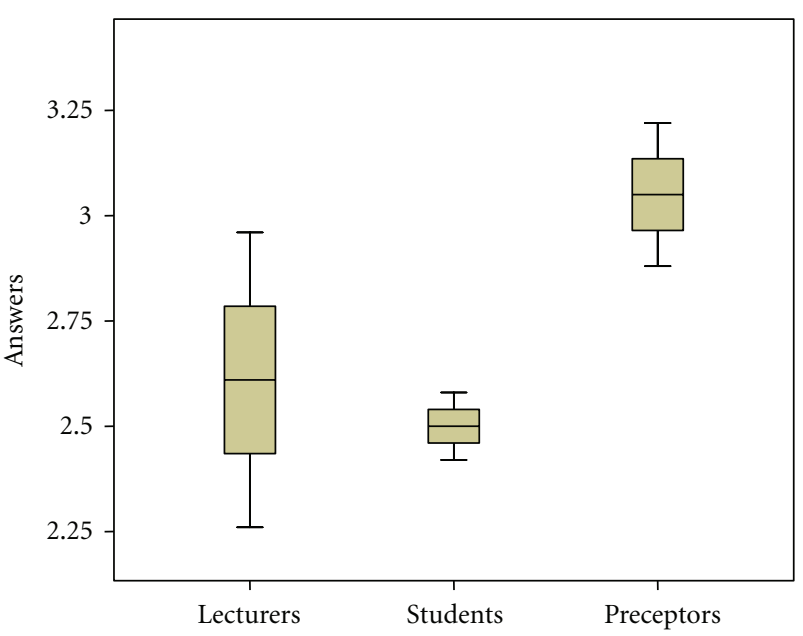

FIGURE 3: Boxplot for the teaching and learning scenarios indicator.

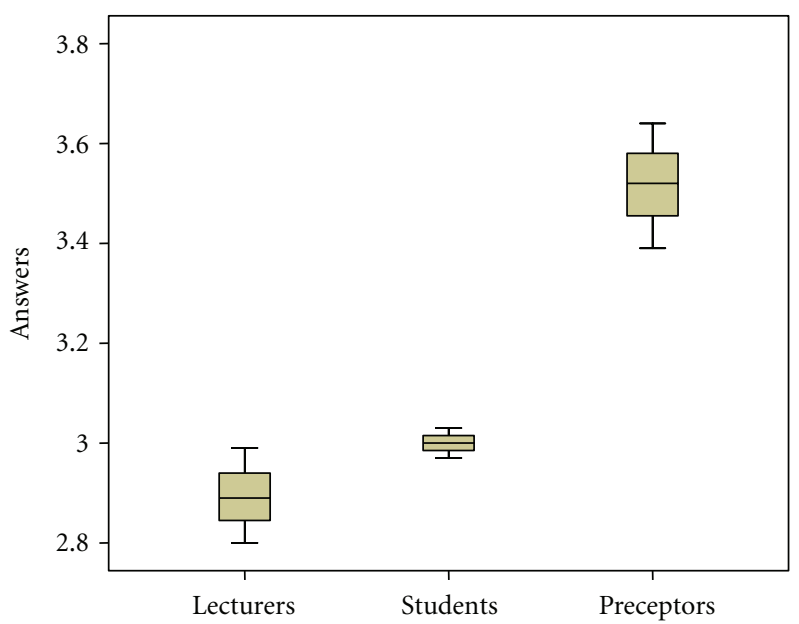

FIGURE 4: Boxplot for the integration of theory and practice indicator.

lecturers and students that is student-centred and respects the group process steps of problem-based learning for the construction of significant learning. In addition, students felt that preceptors often encourage the students to take a proactive approach in practical scenarios and to use their prior knowledge to form new meanings. Regarding the actual or simulated situations, the lecturers believed that these situations are usually realistic and encourage the development of the capacity to identify and deal with problems, as observed in the constructivist approach to the teaching and learning process, which views learning as an activity in context [4].

According to Gonczi [6], conceptualised competency "[links] the attributes of individuals (knowledge, skills, dispositions, values) to the demands of tasks and activities which individuals were undertaking in some aspect of their lives." This concept is best described as an integrated approach; it is relational in that it combines the general with the vocational and the generic with the specific. Competency-based approaches 


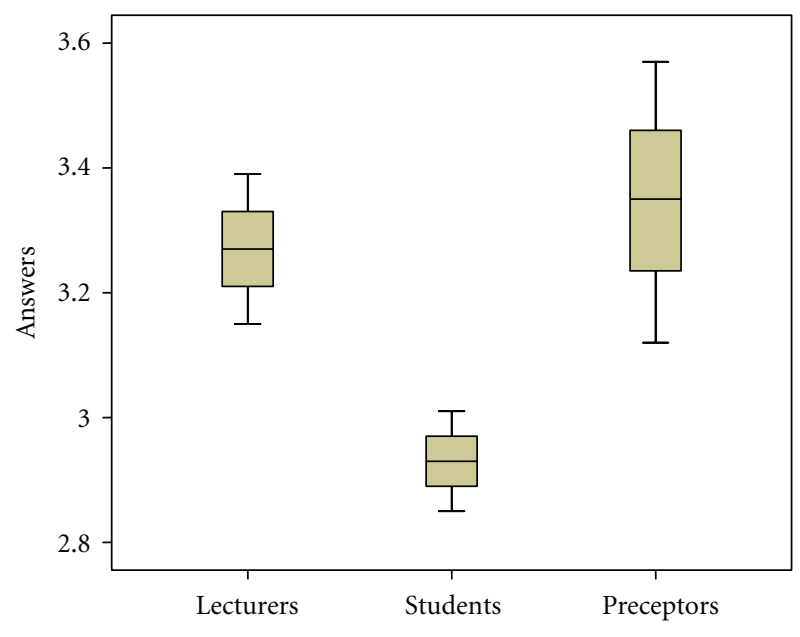

Figure 5: Boxplot for the assessment indicator.

allow for highly individualised learning processes, transparent standards and increased public accountability $[3,11]$. The UFSCar School of Medicine's curriculum is competencybased, meaning that it uses professional practice as a reference for selecting educational content and experiences aimed at developing professional excellence. According to the lecturers, the activities rarely allow for the exploration of a performance set in the competency profile as it relates to the collective health, management and education needs but usually allow the exploration of individual health needs. Students usually felt that the UFSCar medical education curriculum contributed to the development of competency during professional training. According to students, simulation or actual situations always favour group participants' relation with reality and development of the capacity to identify and deal with problems. These situations further facilitate exploration of performance in the competency profile as it relates to education in individual and collective health needs, but exploration of management is rarely possible. According to the preceptors, actual situations frequently facilitate exploration of performance as it relates to individual and collective health needs.

According to Almeida [12], scenarios are spaces of "creation, which allow teaching-performing and learning-working, overcoming the theory and practice dichotomy and creating favourable conditions for action-reflection-action as an intervention model in the teaching and learning process and in collaborative and solidarity work between social subjects, the University, services and community." The majority of lecturers and students rarely viewed teaching and learning scenarios as adequate. Students stated that immersion in fields of professional practice rarely allows them to become members of an interdisciplinary team and does not allow or encourage participation in the development of educational practices in healthcare or in research projects. One explanation of this finding may be the high expectation that students have in relation to the study of pathologies and the care of the sick in hospitals. This position is understandable, as the hospital environment has historically been a privileged area of practice. This opinion has been questioned due to the likely biological reductionism provided by the biomedical model, coupled with the expectation of consumption of high-density technology. Another explanation may be students' immersion in real-life work, which brings its own limitations and complexities. Although this scenario may not always occur, students should expect to contribute to changes in health practices and to be perceived by healthcare professionals and the community as collaborators rather than spectators. The preceptors also noted that the teaching and learning scenarios in which students participate rarely allow them to work on research projects that enable the production of socially relevant knowledge and changing realities. Students' immersion in teaching and learning scenarios has encouraged work in healthcare, despite shortcomings perceived by respondents in practical scenarios. This strategy of inserting students into these three domains of the healthcare system has been adopted by Brazilian Schools of Medicine to expand medical education beyond the hospitalcentred model. This incorporation has occurred through cooperation with municipal health departments and has promoted the development of partnerships between these entities and universities, thereby facilitating the creation of new scenarios in community and health care settings beyond the hospital environment at the primary and secondary care levels present throughout programmes.

To produce meaningful learning, educational experiences must integrate theory and practice using simulated practice situations (laboratories) to allow the exploration of content relevant to competency development and immersing students in real-life professional situations [1]. Therefore, incorporating a new approach to the theory and practice relationship is necessary in recognition of the complex and uncertain nature of problems in the healthcare area in particular. In this sense, the interdisciplinary and interlocution of knowledge that emerges in practical problems is not only an alternative to disciplinary dialogue but also a redefinition and construction of new objects of professional knowledge and intervention in health [13]. Based on the lecturers' perceptions, students usually experience theory and practice together from the beginning of the course and are immersed in the realities of the profession to stimulate the formation of links and correspondences between theory and practice. The students report always being accompanied by preceptors who are immersed in healthcare services on a daily basis and usually experiencing theory and practice concurrently from the beginning of the programme. The preceptors' view is that students always experience theory and practice in an integrated and articulated form from the beginning of the course onwards.

The approach to assessment in constructivism is formative and cumulative. The developed assessment process allows the recognition of potential areas that require attention and the search for elements that will maximise learning in formative assessment. In criterion-referenced assessment, the competency profile and excellence criteria are used as references from which the observed performance of each student can be compared and evaluated. Criterion-referenced assessment promotes collaboration and discourages competition among students while establishing a dialogue with 
great educational depth between teachers and students [1419]. Student assessment in this curriculum involves a set of complementary instruments in the following areas of learning: cognitive (knowledge), psychomotor (skills), and affective (attitudes) [14, 16]. Lecturers and preceptors agree that assessment is criterion reference and periodically performed, thereby allowing freedom of expression and promoting feedback for learning improvement. In the constructivist approach, assessment is an on-going activity and a constituent of the teaching and learning process. It should be performed after completing all activities, by all involved, facilitating the correction of weaknesses [14-19]. Each student's learning pace is respected as much as possible, and progress-oriented assessments (cumulative assessment) are driven by the competency profile, parameters with which perceived performance may be compared. Assessments with predominantly cumulative features are conducted through formal learning verification instruments; they provide assessment indicating the possibility of student progress in the curriculum [16-18].

In this study, we compared preceptor, lecturer, and student views of curriculum implementation at UFSCar's School of Medicine based on the following study indicators: teaching and learning process; integration of competency areas; teaching and learning scenarios; integration of theory and practice; and assessment. These results show that lecturers and students agreed on almost all indicators, with the exception of criterion-referenced assessment, for which the opinions of lecturers and preceptors that were statistically equal. Preceptors, lecturers, and students agreed that the teaching and learning process often favours the construction of a participatory relationship between preceptors and students and that it usually respects the group process steps of problembased learning, thereby enabling significant learning. While students and preceptors often view real-life situations as allowing for exploration of performance sets in the competency profile concerning the collective health needs, lecturers rarely express this opinion. Students and lecturers agree that real-life situations rarely allow for exploration of the performance set in the management competency profile, while preceptors consider that such situations usually allow performance exploration. Considering the implementation process of UFSCar's medical education curriculum from the perspective of the different roles involved, we conclude that aspects related to the teaching and learning process, integration of theory and practice, and assessment are similar to those proposed in the education programme, while integration of competency areas and teaching and learning scenarios require greater attention to establish consistency with the education programme and training.

\section{Appendix}

For more details see Table 6 .

\section{Ethical Approval}

This study was approved by the UFSCar's Research Ethics Committee.
TABLE 6: Description of study indicators.

\begin{tabular}{|c|c|}
\hline Indicator & Descriptor \\
\hline $\begin{array}{l}\text { Integration of competency } \\
\text { areas }\end{array}$ & $\begin{array}{l}\text { Simultaneous occurrence of actions } \\
\text { developed in educational units } \\
\text { covering the following three } \\
\text { competency areas: care (individual } \\
\text { and collective), management } \\
\text { (organisation of work and care } \\
\text { management), and education. }\end{array}$ \\
\hline $\begin{array}{l}\text { Integration of theory and } \\
\text { practice }\end{array}$ & $\begin{array}{l}\text { Linking the professional practice and } \\
\text { practice simulation units beginning } \\
\text { in the first year of training. }\end{array}$ \\
\hline $\begin{array}{l}\text { Development of } \\
\text { pedagogical actions } \\
\text { involving different } \\
\text { learning scenarios }\end{array}$ & $\begin{array}{l}\text { Experience in home care, } \\
\text { ambulatory, prehospital, hospital, } \\
\text { emergency, school, kindergarten, } \\
\text { nursing home, and other settings. }\end{array}$ \\
\hline $\begin{array}{l}\text { Constructivist approach to } \\
\text { the teaching and learning } \\
\text { process }\end{array}$ & $\begin{array}{l}\text { Construction and meaning of } \\
\text { knowledge from exposure to real or } \\
\text { simulated situations that encourage } \\
\text { the development of critical reflective } \\
\text { capacities and the capacity to learn } \\
\text { how to learn, based on principles of } \\
\text { adult learning and active } \\
\text { methodologies. }\end{array}$ \\
\hline $\begin{array}{l}\text { Criterion-referenced } \\
\text { assessment and cumulative } \\
\text { and formative perspective }\end{array}$ & $\begin{array}{l}\text { Assessment is qualitative and involves } \\
\text { the use of criteria defined in the } \\
\text { competency profile for the } \\
\text { educational cycle. The cumulative } \\
\text { perspective comprises verification } \\
\text { through formal learning instruments } \\
\text { and represents assessments that } \\
\text { indicate the possibility of student } \\
\text { progress in the curriculum. The } \\
\text { formative perspective is achieved } \\
\text { during the process and aims to } \\
\text { identify strengths and areas requiring } \\
\text { attention. It should be carried out } \\
\text { after completing all teaching and } \\
\text { learning activities. }\end{array}$ \\
\hline
\end{tabular}

\section{Conflict of Interests}

The authors declare that there is no conflict of interests.

\section{Authors' Contribution}

A. G. Aquilante, R. F. da Silva, M. B. B. de Souza, and R. G. B. Kishi contributed equally to the conception of this paper, review of literature, data collect, data analysis, and drafting and revision of the paper.

\section{Acknowledgment}

The authors wish to thank the team of Centro de Estudos do Risco (CER) at UFSCar's Department of Statistics (DEsCCET) for statistical analysis. 


\section{References}

[1] UFSCar, "Coordenação do Curso de Medicina," Caderno do curso de medicina, UFSCar, São Carlos, Brazil, 2008.

[2] P. E. Doolittle and D. Hicks, "Constructivism as a theoretical foundation for the use of technology in social studies," Theory and Research in Social Education, vol. 31, no. 1, pp. 72-104, 2003.

[3] W. C. Leung, "Competency based medical training: review," British Medical Journal, vol. 325, no. 7366, pp. 693-695, 2002.

[4] T. Duffy and D. Cunningham, "Constructivism: implications for the design and delivery of instruction," in Handbook of Research for Educational Communications and Technology, D. H. Jonassen, Ed., pp. 170-198, Simon and Schuster, New York, NY, USA, 1996.

[5] N. Radomski and J. Russell, "Integrated case learning: teaching clinical reasoning," Advances in Health Sciences Education, vol. 15, no. 2, pp. 251-264, 2010.

[6] A. Gonczi, "Teaching and learning of the key competencies," in Definition and Selection of Key Competencies, Swiss Federal Statistical Office, Ed., pp. 119-131, SFSO, Neuchâtel, Switzerland, 2003, http://www.oecd.org/dataoecd/48/20/41529505.pdf.

[7] A. S. Palincsar, "Social constructivist perspectives on teaching and learning," Annual Review of Psychology, vol. 49, pp. 345375, 1998.

[8] B. Efron, "Bootstrap methods: another look at the jackknife," Annals of Statistics, vol. 7, no. 1, pp. 1-26, 1979.

[9] J. V. Wertsch and P. Tulviste, "L. S. Vygotsky and contemporary developmental psychology," Developmental Psychology, vol. 28, no. 4, pp. 548-557, 1992.

[10] T. Harland, "Vygotsky's zone of proximal development and problem-based learning: linking a theoretical concept with practice through action research," Teaching in Higher Education, vol. 8, no. 2, pp. 263-272, 2003.

[11] L. D. Gruppen, R. S. Mangrulkar, and J. C. Kolars, Competency-Based Education in the Health Professions: Implications for Improving Global Health, University of Michigan, 2010.

[12] M. J. Almeida, "Educação médica e saúde: limites e possibilidades das propostas de mudança," Interface-Comunicação, Saúde, Educação, vol. 2, pp. 214-215, 1998.

[13] V. V. Lima, "Competência: distintas abordagens e implicações na formação de profissionais de saúde," InterfaceComunicação, Saúde, Educação, vol. 9, no. 17, pp. 369-379, 2005.

[14] J. Hoffman, Avaliação mediadora: uma prática em construção da pré-escola à universidade, Educação e Realidade, Porto Alegre, Brazil , 1993.

[15] B. R. Worthen, J. R. Sanders, and J. L. Fitzpatrick, Program Evaluation: Alternative Approaches and Practical Guidelines, Longman, New York, NY, USA, 2nd edition, 1997.

[16] P. Perrenoud, "From formative evaluation to a controlled regulation of learning. Towards a wider conceptual field," Assessment in Education: Principles Policy and Practice, vol. 5, no. 1, pp. 85-102, 1998.

[17] J. E. Romão, Avaliação dialógica: desafios e perspectivas, Cortez, Instituto Paulo Freire, São Paulo, Brazil, 1999.

[18] W. Crebbin, "What do you mean by "satisfactory"?" Annals of the Academy of Medicine Singapore, vol. 34, no. 8, pp. 473-477, 2005.

[19] P. Henderson, A. C. Ferguson-Smith, and M. H. Johnson, "Developing essential professional skills: a framework for teaching and learning about feedback," BMC Medical Education, vol. 5, article 11, 2005. 

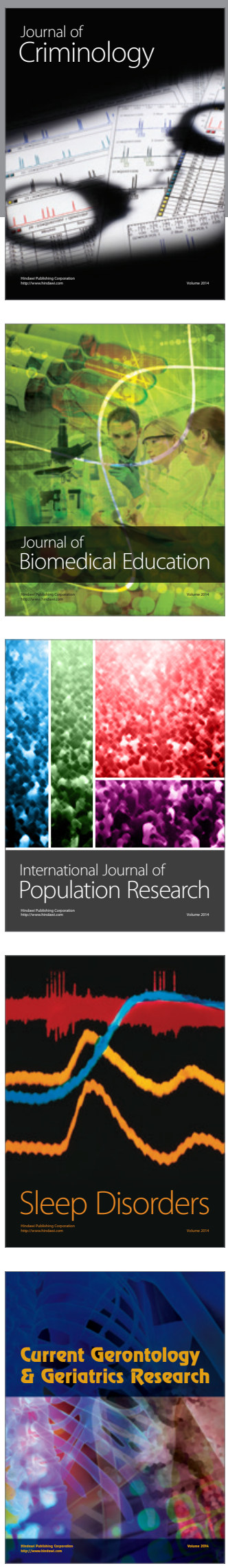
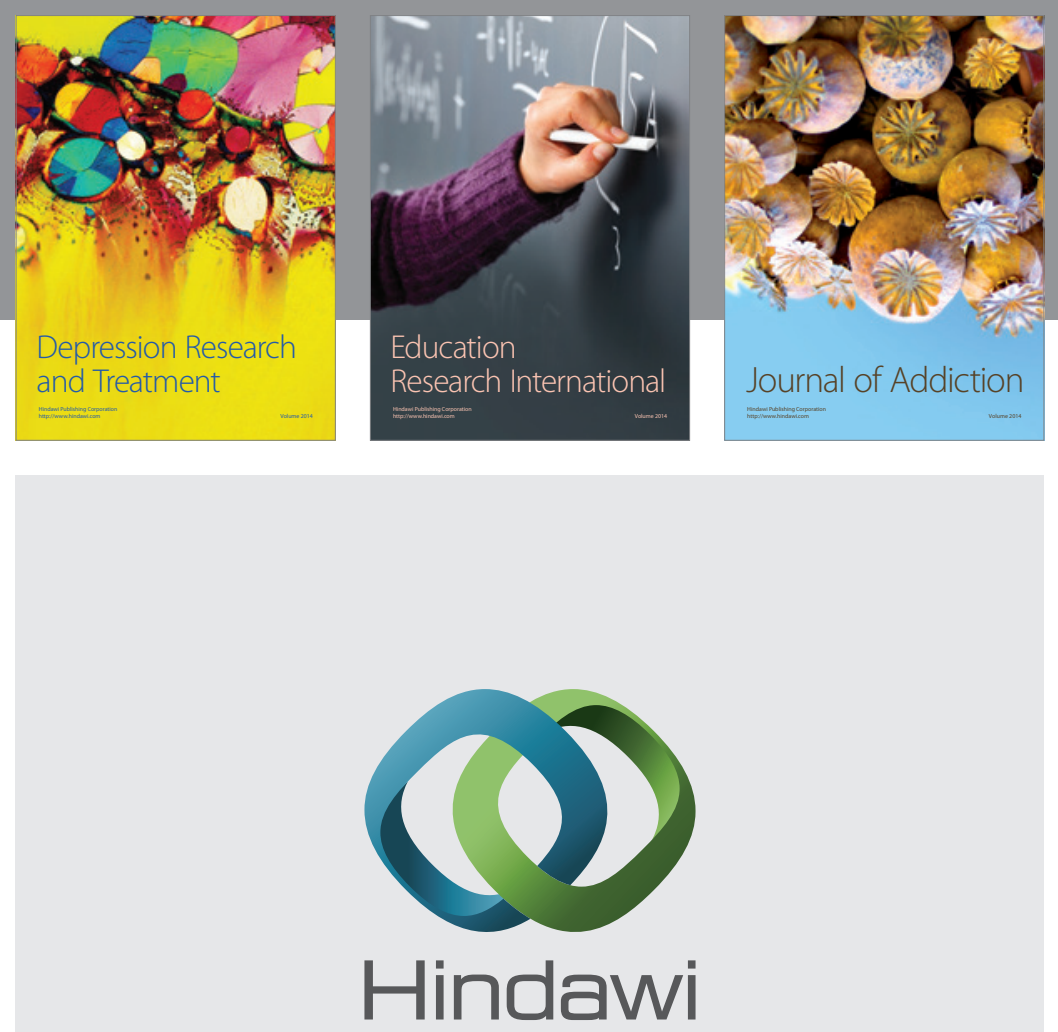

Submit your manuscripts at

http://www.hindawi.com

Child Development Research
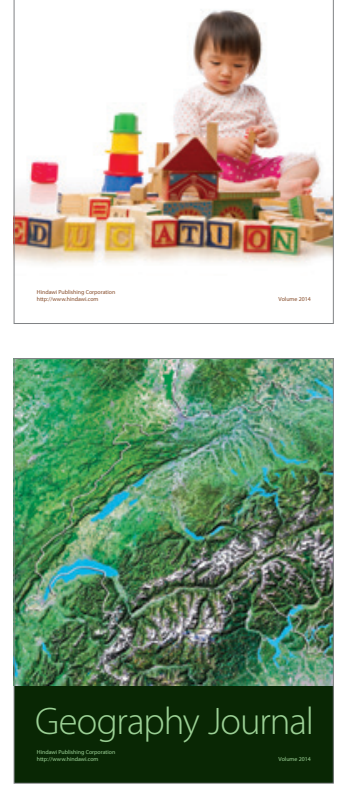

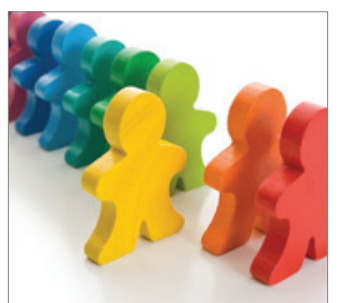

Autism

Research and Treatment
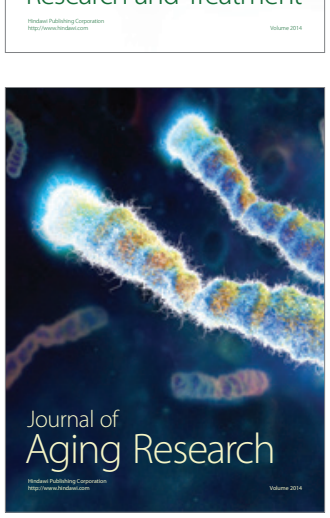
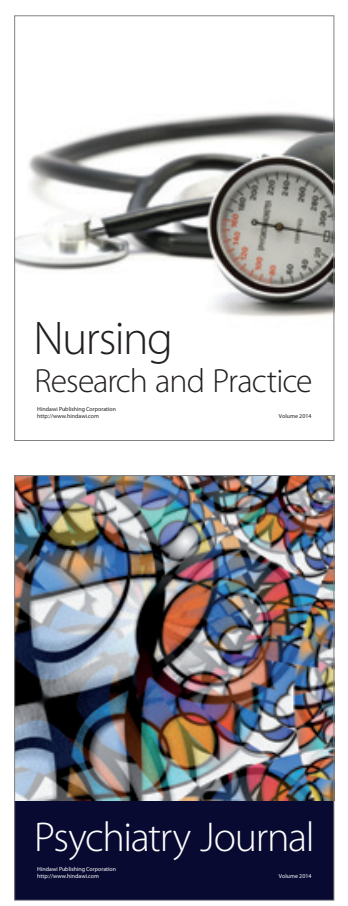
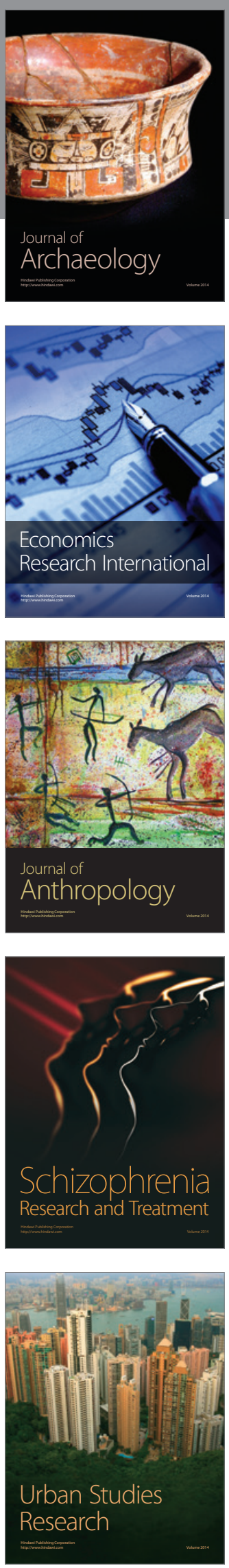